\title{
基于高电导率石墨烯膜的低功耗柔性应变传感器
}

王哲 ${ }^{1,2}$, 李鹏 ${ }^{1}$, 何大平 $1,3^{*}$

1. 武汉理工大学理学院, 湖北省射频微波应用工程技术研究中心, 武汉 430070;

2. 武汉理工大学理学院, 新材料力学理论与应用湖北省重点实验室, 武汉 430070;

3. 武汉理工大学材料复合新技术国家重点实验室, 武汉 430070

* 联系人, E-mail: hedaping@whut.edu.cn

\section{Low-power flexible strain sensors based on highly conductive graphene films}

\author{
Zhe Wang ${ }^{1,2}$, Peng $\mathrm{Li}^{1} \&$ Daping $\mathrm{He}^{1,3^{*}}$ \\ ${ }^{1}$ Hubei Engineering Research Center of RF-Microwave Technology and Application, School of Science, Wuhan University of Technology, Wuhan 430070, \\ China; \\ ${ }^{2}$ Hubei Key Laboratory of Theory and Application of Advanced Materials Mechanics, School of Science, Wuhan University of Technology, Wuhan 430070, \\ China; \\ ${ }^{3}$ State Key Laboratory of Advanced Technology for Materials Synthesis and Processing, Wuhan University of Technology, Wuhan 430070, China \\ * Corresponding author, E-mail: hedaping@ whut.edu.cn \\ doi: 10.1360/TB-2020-0960
}

人们往往通过感觉器官(如眼睛、耳朵、鼻子、舌头、 皮肤等)获得外界信息. 然而, 随着科技的日益发展, 人体 的感官已经不能满足生产活动中高精度测量的应用需求, 各类型的传感器应运而生. 作为传感器的一个分支, 应变 传感器用于定量探测物体表面的变形, 在可穿戴电子设 备、机器人、人体健康监护系统、语音康复训练系统等领 域, 展现出巨大的应用潜力. 应变传感器可以分为电容 式、压电式、电阻式、摩擦生电式四种类型 ${ }^{[1]}$. 其中, 电阻 式传感器凭借制备难度低、易于测量的优势, 得到了研究 者的青睐. 目前, 基于金属材料和导电高分子材料的电阻 式应变传感器研究取得了较大的进展. 但是, 这两种材料 在应用上均存在各自的局限性: 金属材料的密度大, 化学 稳定性和柔性差, 而导电高分子材料往往具有较差的电导 率. 针对此现状, 本研究团队采用了一种新型碳材料一 多孔石墨烯膜材料制备传感器, 解决了上述的问题. 此外, 这种石墨烯膜传感器既可以检测气流, 也能进行发音识别, 且具有低功耗及大规模应用的前景, 相关研究成果发表在 Science Bulletin 上 $^{[2]}$.

\section{1 神奇石墨烯, 助力传感器}

近年来, 有关石墨烯材料的研究和应用日新月异. 那 么, 究竟什么是石墨烯呢? 石墨烯通常指的是单层石墨烯, 即一种由单层碳原子以 $\mathrm{sp}^{2}$ 杂化轨道排列、呈六角形蜂巢状
晶格的二维纳米材料 ${ }^{[3]}$. 单层石墨烯于 2004 年由英国曼彻 斯特大学的 Geim 和 Novoselov 两位物理学家发现. 他们也 因此获得 2010 年诺贝尔物理学奖. 石墨烯能够让其发现 者获得如此殊荣, 可见这种材料必定有其神奇之处. 室温 下石墨烯的电子迁移率为 $2.5 \times 10^{5} \mathrm{~cm}^{2} \mathrm{~V}^{-1} \mathrm{~s}^{-1[3]}$, 理论电导 率高达 $10^{8} \mathrm{~S} \mathrm{~m}^{-1}$, 比常见金属的电导率还要高 1 个数量 级 ${ }^{[4]}$. 此外, 二维结构赋予了石墨烯材料良好的柔韧性. 因此, 石墨烯材料用于制备电阻式传感器具有巨大的 潜力.

传统的基于石墨烯材料应变传感器往往是将石墨烯 材料与柔性基底(如聚二甲基硅氧烷、纺织物、弹性带及纤 维等)进行复合. 一方面, 由于工艺的限制, 石墨烯的接触 电阻较大, 电导率较低, 导致传感器使用时功耗增加; 另 一方面, 传感器依托于柔性基底, 增加了成本, 大规模应 用制备也容易受到限制. 围绕这些难题, 本研究组通过设 计并制备得到多孔石墨烯膜材料, 实现了无基底传感器的 制备, 并大幅度降低了传感器的功耗.

\section{2 多孔薄膜传感器，牵一发而动全身}

不同的制备工艺赋予石墨烯膜独有的性能. 那么, 这 种高电导率的多孔石墨烯膜材料究竟是怎样实现的呢? 对 于还原法制备的宏观石墨烯膜而言，石墨烯材料的含氧基 团和缺陷往往导致电导率的大幅度下降. 针对这个问题, 
本研究团队在前期工作中发现, 通过控制热处理工艺的温 度, 可以调控石 墨烯材料含氧量 ${ }^{[5]}$, 进而实现高电导率石 墨烯膜材料的制备. 此外, 在高温热处理的过程中, 石墨 烯材料中的碳原子会发生重排, 实现缺陷的自愈合, 从而 增加电导率. 同时, 石墨烯材料的含氧基团会在高温环境 中转变为一氧化碳、二氧化碳等气体 ${ }^{[6]}$. 这些气体逐渐聚 集并从石墨烯膜表面逸出, 导致石墨烯膜表面存在许多微 褶皱, 并整体呈现多孔结构. 基于上述机理, 具有高电导 率的多孔石墨烯膜材料就可以制备得到. 目前实验室可以 实现面积达数平方分米的石墨烯膜制备.

石墨烯膜是由许多微观石墨烯纳米片搭接组装而成. 当石墨烯膜的任意区域产生拉伸形变时, 形变将在薄膜的 多孔结构中通过片层间的相对滑移不断传递, 从而增加其 接触电阻. 所谓“牵一发而动全身”, 即整个传感器电阻值 将随着形变的增大而产生线性叠加. 这正是石墨烯膜应变 传感器的工作原理. 石墨烯膜表面存在的微擢皱, 赋予了 石墨烯膜良好的柔韧性. 当石墨烯膜受到力的作用时, 这 些微褶皱会被扯平, 给整体结构提供缓冲. 因此, 石墨烯 膜可以经受随意地折揉以及成百上千次的弯折, 并维持结 构和电导率的稳定. 既然自支撑式的石墨烯膜本身就具有 良好的柔韧性, 那么在制备基于石墨烯膜的应变传感器过 程中, 就可以简化并舍去柔性基底这一组分了. 如此, 传 感器的制备工艺更加简单, 节省了时间并且成本更低. 此 外, 经历了高温处理的石墨烯膜, 随着温度的升高 $\left(20^{\circ} \mathrm{C} \rightarrow\right.$ $100^{\circ} \mathrm{C}$ ), 其电阻保持不变, 展现出优异的热稳定性. 这个 特性对于应变传感器而言, 是难能可贵的.

虽然具有多孔结构的石墨烯膜用于应变传感器在理 论上可行, 但是这种新型材料在实践中又有什么样的表现 呢? 围绕这个问题, 本研究组将铜电极铺设于一定长度的 石墨烯膜两端, 同时用导电银胶固定, 制备出石墨烯膜应 变传感器, 并开展了多项测试. 我们研究了石墨烯膜传感 器的传感标准因子, 发现其与传统商业金属应变片的传感 标准因子相当, 能够满足相关的应用需求. 石墨烯膜传感
器在周期性不同应变状态下呈现出对应周期性的传感曲 线, 且在拉伸循环测试中展现出良好的可重复性.

令人惊喜的是, 石墨烯膜不仅可以用作应变传感器, 还能应用于压力传感器. 研究发现, 石墨烯膜压力传感器 的性能与石墨烯膜厚度、所受压力有关. 单一变量的条件 下，石墨烯膜厚度越大，或者所受压力越大，传感效果越 好. 另外, 测试结果显示, 铜导线的变形几乎不会改变传 感器整体的电阻, 因此不会影响传感器的性能. 值得注意 的是, 当操作电压仅为 5 号电池工作电压的 1/150(0.01 V) 时, 石墨烯膜传感器也能满足测试需求. 这是由于多孔石 墨烯膜具有高电导率, 优于绝大多数已报道的碳基传感器. 可以预见, 在未来的绿色科技发展中, 低功耗特性将赋予 石墨烯膜传感器更强的竞争力.

这些基础性能证明了石墨烯膜传感器确实具有可行 性, 那么它们的应用效果怎么样呢? 我们将传感器附在测 试者的喉部，当测试者针对“Hi”“Good”和“Okay”等不同 的英语单词发音时, 得到 3 种独特且可再现的信号, 展现 出传感器在语音康复训练的应用前景. 更有意思的是, 石 墨烯膜传感器可以检测出空气的流动. 当测试者面向传感 器吹气时, 也能获得相应的信号. 这使得石墨烯膜传感器 在智能可穿戴电子设备中具有很大的应用潜力.

我们提出了一种基于高电导率多孔石墨烯膜的自支 撑式低功耗应变传感器. 与传统石墨烯基传感器相比, 这 种新型传感器制备工艺简单(减少了组分), 节省时间, 降 低成本, 具有大规模生产的潜力. 然而, 要想实现这种传 感器从实验室走向工厂, 目前还面临着一些挑战. 例如, 石墨烯膜传感器的灵敏度、响应时间等参数仍有待进一步 提升. 此外, 在实际应用中, 配套检测仪器的便携性、工艺 的标准化等因素不容忽视. 而这些挑战, 也给了研究者奋 斗的目标. 道路是曲折的, 前途是光明的. 相信这些新型 传感器能够在未来的可穿戴电子设备、机器人、人体健康 监护系统、语音康复训练系统等领域, 扮演着更重要的 角色.

\section{推荐阅读文献}

1 Wang C, Xia K, Wang H, et al. Advanced carbon for flexible and wearable electronics. Adv Mater, 2019, 31 : 1801072

2 Wang Z, Li P, Song R, et al. High conductive graphene assembled films with porous micro-structure for freestanding and ultra-low power strain sensors. Sci Bull, 2020, 65: 1363-1370

3 Novoselov K S, Fal V I, Colombo L, et al. A roadmap for graphene. Nature, 2012, 490: 192-200

4 Scida A, Haque S, Treossi E, et al. Application of graphene-based flexible antennas in consumer electronic devices. Mater Today, 2018, 21: $223-230$

5 He D, Cheng K, Peng T, et al. Bifunctional effect of reduced graphene oxides to support active metal nanoparticles for oxygen reduction reaction and stability. J Mater Chem, 2012, 22: 21298-21304

6 Li P, Wang Z, Song R, et al. Customizable fabrication for auxetic graphene assembled macrofilms with high conductivity and flexibility. Carbon, 2020, 165: 545-551 